\title{
Hot isostatic pressing of single-crystal nickel-base superalloys: Mechanism of pore closure and effect on Mechanical properties
}

\author{
Alexander I. Epishin ${ }^{1, a}$, Thomas Link ${ }^{1}$, Bernard Fedelich ${ }^{2}$, Igor L. Svetlov ${ }^{3}$, and Evgeniy R. Golubovskiy ${ }^{4}$ \\ ${ }^{1}$ Technical University of Berlin, Institute of Material Science and Technology, Ernst-Reuter-Platz 1, 10587 Berlin, \\ Germany \\ ${ }^{2}$ Federal Institute for Materials Research and Testing (BAM), Unter den Eichen 87, 12205 Berlin, Germany \\ ${ }^{3}$ All-Russian Institute of Aviation Materials (VIAM), Radio Str. 17, 105005 Moscow, Russia \\ ${ }^{4}$ Central Institute of Aviation Motors (CIAM), Aviamotornaya Str. 2, 111116 Moscow, Russia
}

\begin{abstract}
Pore annihilation was investigated in the single-crystal nickel-base superalloy CMSX-4. HIP tests at $1288^{\circ} \mathrm{C} / 103 \mathrm{MPa}$ were interrupted at different times, then the specimens were investigated by TEM, metallography and density measurements. The kinetics of pore annihilation was determined. The pore closure mechanism was identified as plastic deformation on the octahedral slip systems. A model describing the kinetics of pore closure has been developed on the base of crystal plasticity and large strain theory. Mechanical tests with the superalloy CMSX-4 and the Ru-containing superalloy VGM4 showed, that HIP significantly increases the fatigue life at low temperatures but has no effect on creep strength.
\end{abstract}

\section{Introduction}

Single crystal turbine blades cast from nickel-based superalloys contain pores. These pores form at different steps of blade manufacturing (solidification, homogenization) and grow under long-term high temperature loading (creep conditions) [1]. The most dangerous are large solidification pores. Industrial manufacturing of single-crystal blades is performed by the Bridgeman method with a temperature gradient of $5-20^{\circ} \mathrm{C} / \mathrm{mm}$ and a withdrawal rate of $3-25 \mathrm{~mm} / \mathrm{min}$ depending on the cooling method. Under such solidification conditions the superalloy crystal grows by dendritic growth which has the side effect, that pores form between the developing dendritic arms. These pores are critical if they are large (they can be up to hundred microns in length) and located close to the blade surface.

Porosity in materials can be removed by hot isostatic pressing (HIP), a technique, which is now applied industrially for processing of single-crystal turbine blades. However, because this application of HIP to single-crystal material is new and very special, there are several opened questions concerning this technique. Some of them are considered in the present work.

Single-crystal blades are HIPed at temperatures close to solidus, which bears the risk of recrystallisation and incipient melting. Single-crystal blades are expensive and the price of HIP is high as well. Therefore the parameters of industrial HIP (temperature $T$, pressure $p$, duration $t$ ) have to be carefully optimized under the conditions of complete pore annihilation, avoiding of material damage and minimization of processing costs.

\footnotetext{
${ }^{a}$ Corresponding author: alex_epishin@yahoo.de
}

Such a HIP optimization could be simplified, if the kinetics of pore annihilation would be known and the pore closure mechanism identified, because this would allow to develop a numerical model for pore closure and then to study the effect of the different HIP parameters on the kinetics of pore annihilation. Therefore the first task of this work was to determine the kinetics of pore annihilation, to clarify the micromechanisms of pore closure and then develop a model describing the observed kinetics.

The second task of this work concerns the effect of HIP on mechanical properties of single-crystal nickelbase superalloys. Reliable data on this effect are important for modeling the lifetime of HIPed blades, however the literature data concerning this effect are contradictory. Therefore mechanical tests of unHIPed and HIPed material were performed, where special care was taken regarding the effect of HIP on the $\gamma / \gamma^{\prime}$-morphology. The results were compared with literature data about the HIP effect.

\section{Experimental}

Materials under investigation were a nickel-base superalloy of the $2^{\text {nd }}$ generation, CMSX-4 (C-M, USA) [2] and a $\mathrm{Ru}$-containing single-crystal nickel-base superalloy of the $4^{\text {th }}$ generation, VGM4 (VIAM, Russia) [3]. [001] singlecrystals of CMSX-4 were solidified by Howmet Castings, Alcoa, USA, [001] single-crystals of VGM4 by VIAM. A batch of these specimens was first heat treated and then used for interrupted HIP experiments (only CMSX-4) and mechanical testing (all superalloys). The other part was first HIPed and then heat treated, in order to attain the same

This is an Open Access article distributed under the terms of the Creative Commons Attribution License 4.0, which permits unrestricted use, distribution, and reproduction in any medium, provided the original work is properly cited. 
$\gamma / \gamma^{\prime}$-morphology as in the standard condition, afterwards it was used for mechanical testing.

The HIP experiments with CMSX-4 were performed in the HIP plant QIH-16, ASEA at $1288^{\circ} \mathrm{C} / 103 \mathrm{MPa} / 6 \mathrm{~h}$ in argon, as used by Howmet Castings for CMSX-4. In order to investigate the kinetics of pore closure, the HIP experiments were interrupted after $0.5,1,2$ and $4 \mathrm{~h}$, but also continued until the full HIP time of $6 \mathrm{~h}$. The HIP temperature used of $1288^{\circ} \mathrm{C}$ is slightly above the $\gamma^{\prime}$-solvus temperature, which is for CMSX-4 about $1280^{\circ} \mathrm{C}$. To be somewhat above the $\gamma^{\prime}$-solvus temperature is advantageous for HIPing, because in such a single phase condition the superalloy is plastically much softer.

The kinetics of pore annihilation in CMSX-4 during HIP was determined indirectly via the increase of density and directly by the decrease of porosity measured by quantitative metallography. The relative decrease of porosity during HIP is identical with the increase of the density $\rho$. To attain the absolute porosity, a heat treated unHIPed specimen with defined porosity was used as reference material. The density was measured by the Archimedes' method, which is based on the different weight of the CMSX-4 cylinder surrounded by air, respectively by water. This technique was refined in our laboratory and a relative accuracy of $\Delta \rho / \rho \approx 10^{-4}$ was attained, sufficient to measure the kinetics of porosity annihilation, which covers a range of about 0.2 vol.\%. Experimental details of the density measurement are given in [4]. In order to verify the results from this indirect method, the kinetics of pore annihilation was measured additionally by quantitative metallography. For this purpose specimens were cut, thoroughly polished, cleaned and then images were taken in a Zeiss Axioscope light microscope at a magnification of 100. 15-20 images were processed with the Olympus software a4i for each porosity data point.

The main aim of the TEM investigations was to find an indication of the pore annihilation mechanism near the pore surface. The investigations were performed in a Philips CM 30 TEM. The mechanism of pore annihilation was checked with a specimen, where the HIP test was interrupted after $0.5 \mathrm{~h}$, because after such a short time one can still find pores, which have shrunk significantly but still not closed completely. In order to attain a TEM foil at such a pore, first the specimen was cross cut and remaining pores were searched on the polished surface. Next, in a focused ion beam (FIB) workstation FIB 200 from FEI, such a pore was filled by deposition of platinum in order to avoid damage during the subsequent foil preparation. Finally, a lamella was cut perpendicular to the specimen surface by the focused ion beam and investigated in TEM.

Mechanical testing included creep and low cycle fatigue (LCF) tests of unHIPed and HIPed specimens of the superalloys CMSX-4 and VGM4. The creep tests with CMSX-4 were performed at $750{ }^{\circ} \mathrm{C} / 780 \mathrm{MPa}$ and $1150{ }^{\circ} \mathrm{C} / 100 \mathrm{MPa}$, those with VGM4 at $1150^{\circ} \mathrm{C} / 100 \mathrm{MPa}$. Strain controlled LCF tests were performed, the CMSX4 tests at $700^{\circ} \mathrm{C}$ with the shape factor of the deformation cycle $R_{\varepsilon}=\varepsilon_{\min } / \varepsilon_{\max }=-1$ and strain rate $10^{-3} \mathrm{~s}^{-1}$, the VGM4 tests at $850{ }^{\circ} \mathrm{C}, R_{\varepsilon}=0$ and frequency $0.5 \mathrm{~Hz}$.

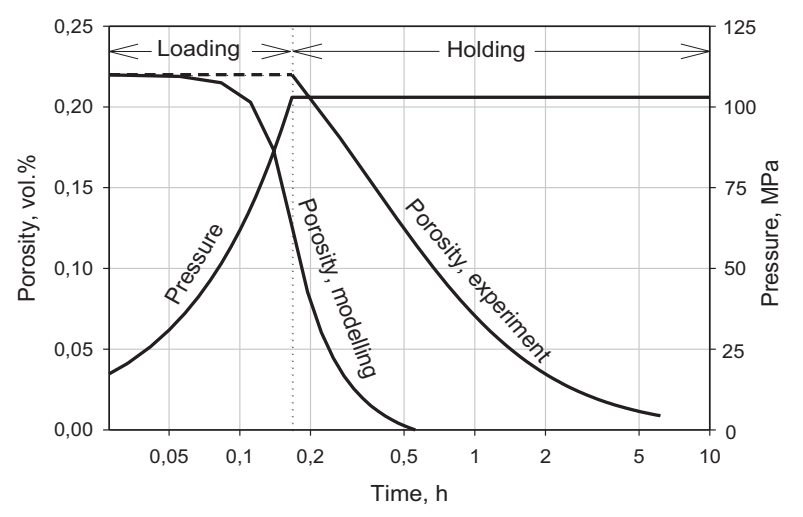

Figure 1. Kinetics of porosity annihilation in CMSX-4 during HIP (loading at $1288^{\circ} \mathrm{C}$ up to $103 \mathrm{MPa}$ and holding at $1288^{\circ} \mathrm{C} / 103 \mathrm{MPa}$ ), experiment and modelling. Because during loading the porosity could not be measured, it is shown by a horizontal dashed line.

\section{Results 1: HIP kinetics and mechanism}

The measurements of the kinetics of pore annihilation in CMSX-4 during HIP at $1288^{\circ} \mathrm{C} / 103 \mathrm{MPa}$ by the density method and quantitative metallography gave very close results. Therefore all obtained data for pore volume fraction $V_{p}$ were approximated by a single hyperbolic function $V_{p}(t)=V_{p}^{0} /(1+t / \tau)^{n}$ of the HIPing time $t$, where $V_{p}^{0}=0.22$ vol. $\%, \tau=40 \mathrm{~min}$ and $n=1.4$ are fitted parameters. The pore annihilation curve $V_{p}=f(t)$ is shown in Fig. 1. Because during loading the porosity could not be measured it is shown by horizontal dashed line.

Figure 2 presents a TEM image of the dislocation structure of superalloy CMSX-4 after $0.5 \mathrm{~h}$ HIP at $1288^{\circ} \mathrm{C} / 103 \mathrm{MPa}$. The image is taken in a distance of about $3 \mu \mathrm{m}$ from the pore surface, with beam direction [12̄1] relative to the foil. Here one can see slip traces visible as straight lines, marked by black arrows. The slip planes are edge on. They are perpendicular to the [111] direction, i.e. they are the typical (111) slip planes of a fcc crystals of nickel. This type of $\{111\}$ slip planes was confirmed at different zone axes, from which follows that the mechanism of pore annihilation is plastic deformation by the octahedral dislocation slip.

\section{Modeling}

The shape of the pores in unHIPed, heat treated CMSX-4 is close to spherical, the porosity volume fraction $V_{p}$ is about 0.22 vol. \%. This geometry is modeled by a sphere, consisting of CMSX-4, with a spherical pore in the center. The ratio of external radius $R_{e}$ of the CMSX-4 ball and the radius $R_{p}$ of the pore corresponds to $V_{p}: R_{p} / R_{e}=$ $\sqrt[3]{V_{p}}=\sqrt[3]{2.2 \cdot 10^{-3}} \approx 1 / 7.7$. On the CMSX-4 ball the external pressure $p$ was applied. Taking into account the cubic symmetry of the fcc lattice of nickel, the computing domain could be reduced down to a $1 / 48^{\text {th }}$ of the complete sphere. It was assumed that under HIP conditions CMSX-4 shows elastoviscous behavior, where the viscous part was modeled by viscous octahedral slip $\langle 01 \overline{1}\rangle\{111\}$, which 


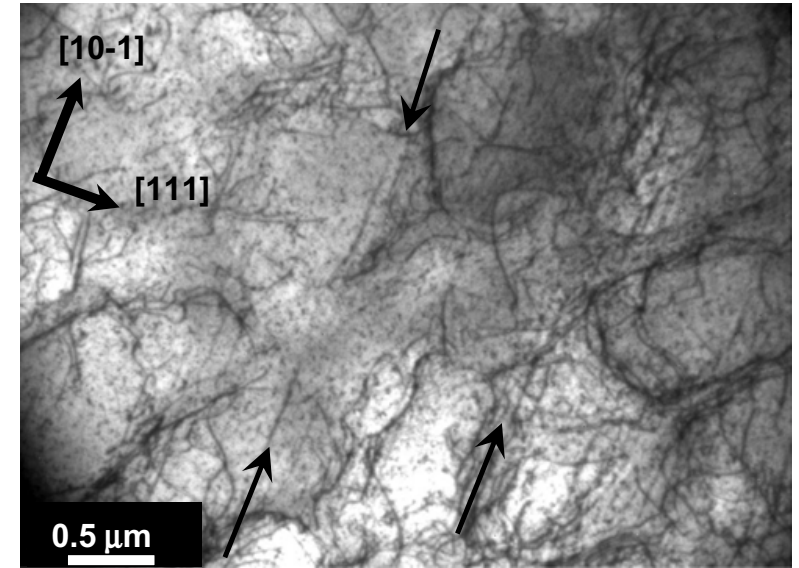

Figure 2. TEM image of CMSX-4 after HIP at $1288^{\circ} \mathrm{C} / 103 \mathrm{MPa} / 0.5 \mathrm{~h}$. (111) slip planes in edge on position, marked by black arrows. $\vec{k}_{0}=[1 \overline{2} 1], \vec{g}=111$. The distance from the pore surface is about $3 \mu \mathrm{m}$.

follows from the anisotropy of the creep tests performed at HIP temperature $1288^{\circ} \mathrm{C}$ [5] as well as from the dislocation structure observed in TEM. Pore closure is accompanied by very strong plastic deformation of the areas around the pore. Therefore, in order to describe such a plastic flow of the material, crystal plasticity theory and large strain theory were employed. The total plastic strain of the material was calculated as the sum of the contributions of all active slip systems, where the plastic shear rate in each slip system was supposed to have a power law dependence on resolves shear stress.

The simulation of the pore shrinking was performed by the finite element method (FEM) program ABAQUS. The simulation consisted of two steps. The first step is the isothermal constant rate loading at $1288^{\circ} \mathrm{C}$ where the hydrostatic pressure reaches a level of $103 \mathrm{MPa}$ within 10 min loading time, the second step is holding the pressure at this temperature for 6 hours (Fig. 1). Figure 3 shows the simulated pore shape immediately after loading and after following holding for $10 \mathrm{~min}$ under the hydrostatic pressure $103 \mathrm{MPa}$. Figure $3 \mathrm{a}$ gives the distribution of Mises stress $\sigma_{M}$, Fig. $3 \mathrm{~b}$ equivalent green plastic strain $\varepsilon^{P}$. In general, $\sigma_{M}$ is low in the HIPed material because it is mostly under $3 \mathrm{D}$ compression. But as it seen in Fig. 3a at the free pore surface $\sigma_{M}$ is high, up to about $60 \mathrm{MPa}$, because the radial stress component vanishes. Therefore, the strong, inhomogeneous $\sigma_{M}$ causes very large plastic deformations in the pore vicinity, which is confirmed by Fig. $3 \mathrm{~b}$ (maximum $\varepsilon^{P}$ between 10 and 35). Because of the anisotropy of the material, the pore shape deviates from sphericity and finally it collapses by bowing the pore surface towards the pore center in weak $\langle 001\rangle$ directions. The modeled kinetics of the porosity decrease is shown in Fig. 1 in comparison with the experimental result. From modeling follows that the pore shrinks significantly already during loading step, which however can not be verified by performed interrupted HIP tests. After loading the modeled and experimental curves have similar shapes, however it is clearly seen that the kinetics of pore shrinking is overestimated by the model.

A detailed description of the modeling procedure and the results is given in [6].
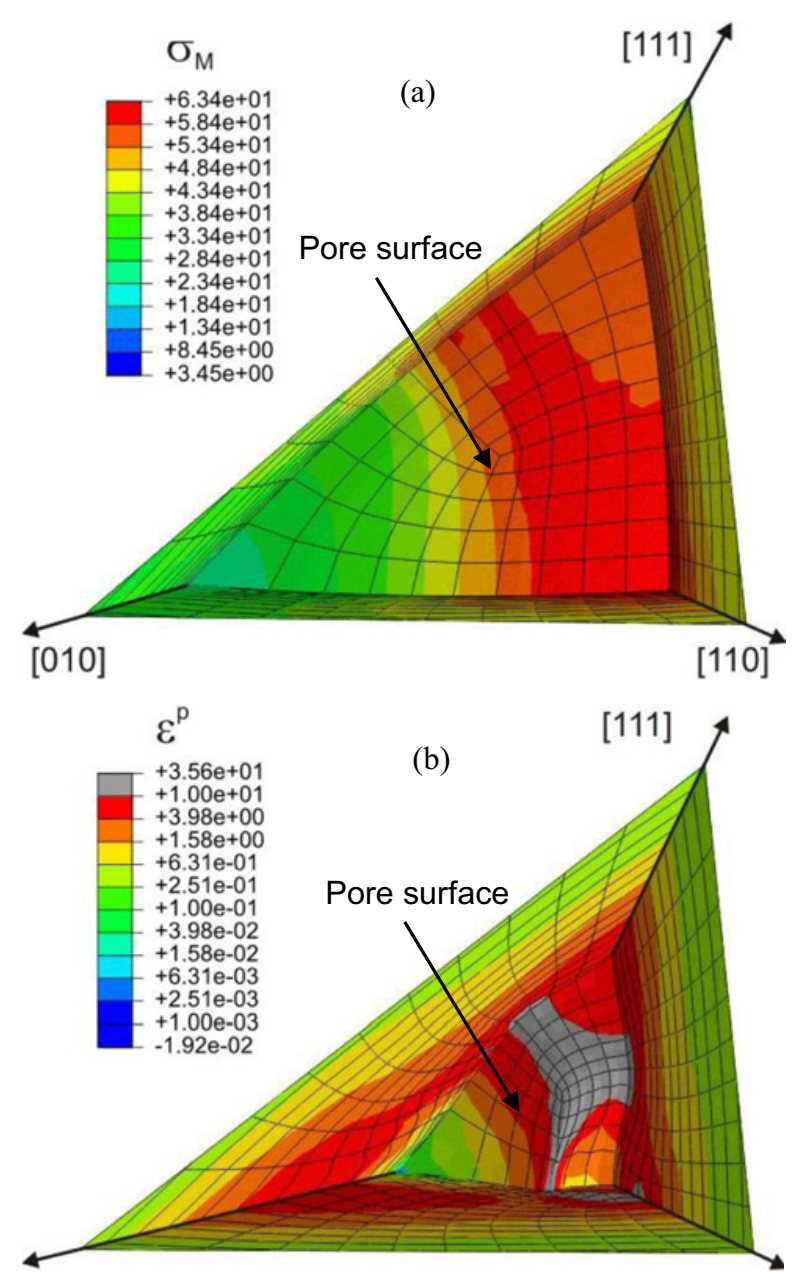

[010]

[110]

Figure 3. Pore shape in superalloy CMSX-4 immediately after loading (a) and after $10 \mathrm{~min}$ holding at $1288^{\circ} \mathrm{C}$ under hydrostatic pressure $103 \mathrm{MPa}$ (b). In (a) distribution of Mises stress is shown, in (b) equivalent Green plastic strain.

\section{Results 2: Effect of HIP on mechanical properties}

As mentioned in the introduction, contradictions were found in publications about the effect of HIP on the mechanical properties of single-crystal nickel-base superalloys. Therefore our mechanical investigations included two types of tests of unHIPed and HIPed material: new tests which were not available in literature and comparative tests for published results.

The most pronounced effect of pore annihilation is expected for tests under cyclic loading, because here the material damage at pores accumulates cycle by cycle. In our work we performed LCF tests of unHIPed and HIPed CMSX-4 at $700{ }^{\circ} \mathrm{C}$ under axial strain controlled loading with $R_{\varepsilon}=-1$. Two tests with a total strain range $\Delta \varepsilon=1.9 \%$ were performed and three tests with $\Delta \varepsilon=$ $1.3 \%$. For $\Delta \varepsilon=1.9 \%$, the number of cycles to failure $(N)$ was equal to 51 for the unHIPed specimen and $N=603$ for the HIPed one, so HIP increased the LCF life by about 12 times. Two tests with $\Delta \varepsilon=1.3 \%$ gave $N=14456$ resp. 16511 for unHIPed specimens and for the HIPed ones 


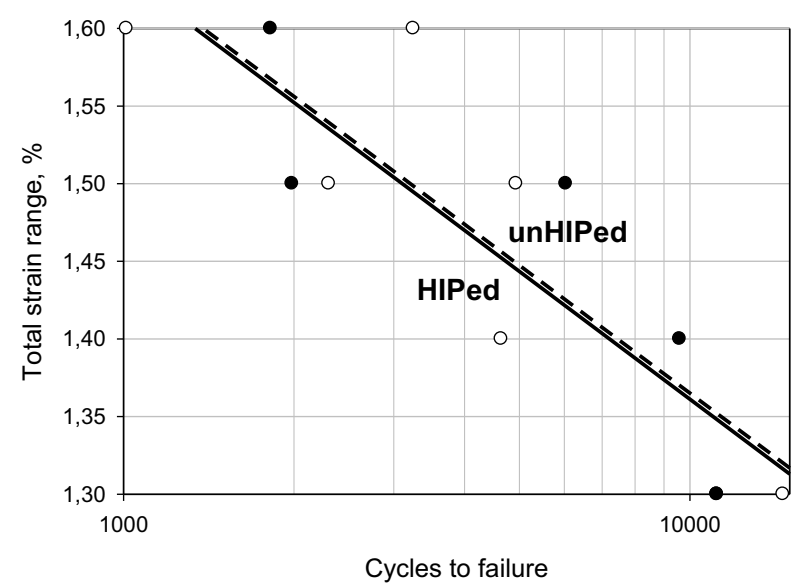

Figure 4. Effect of HIP on LCF life of the superalloy VGM4 at $850^{\circ} \mathrm{C}$. White dots - unHIPed material, black dots - HIPed material. Straight lines are linear regression by $\Delta \varepsilon=a+$ $b \log N$ with fitted parameter $b=-0.2735$ for both conditions. The parameter $a$ is 2.459 respectively 2.455 for the unHIPed resp. HIPed condition.

the test was stopped after 180000 cycles without failure. So for $\Delta \varepsilon=1.3 \%$, HIP increased the LCF life even more. Thus in the case of smaller $\Delta \varepsilon$ HIP resulted in transition from $\mathrm{LCF}$ to high cycle fatigue (HCF) range.

LCF tests of the unHIPed and HIPed superalloy VGM4 were performed at $850^{\circ} \mathrm{C}$ with $R_{\varepsilon}=0$. Six unHIPed specimens and six HIPed specimens were tested at total strain ranges $\Delta \varepsilon$ between $1.3 \%$ and $1.6 \%$. The results of the performed LCF tests are shown in Fig. 4. Because of the large scatter of the black and white points, a special fitting procedure was applied. It was assumed that both data sets follow the same equation $\Delta \varepsilon=a+b \log N$, and that the parameter $b$ is identical for the unHIPed and HIPed condition but the parameter $a$ is different. Such a fitting gave $b=-0.2735$, and $a=2.459$ resp. for the unHIPed condition resp. $\mathrm{a}=2.455$ for HIPed one. From this fitting follows that the predicted LCF lifes of unHIPed and HIPed VGM4 differ only by $3 \%$ which is negligible compared with the scatter of the LCF results.

It was reported in $[7,8]$ that for HIPed superalloy CMSX-4 the minimum creep rate at $1150{ }^{\circ} \mathrm{C} / 100 \mathrm{MPa}$ is reached at a critical strain $0.3 \pm 0.2 \%$, which is about half that for unHIPed condition, $0.7 \pm 03 \%$. We checked this effect at the same condition as well as at $750{ }^{\circ} \mathrm{C} / 780 \mathrm{MPa}$ where superalloys show a pronounced primary creep, up to several \% strain. Two bars of the homogenized superalloy CMSX-4, one unHIPed the other HIPed, both with orientations very close to [001], were selected for these comparative tests. Before the creep test, both bars were subjected to the same heat treatment, namely quenching from $1305^{\circ} \mathrm{C}$ followed by two step aging at $1140{ }^{\circ} \mathrm{C} / 6 \mathrm{~h}$ and $870^{\circ} \mathrm{C} / 16 \mathrm{~h}$. After this heat treatment the specimens had the same regular cuboidal $\gamma / \gamma^{\prime}$-microstructure. It should be emphasized, that in this case quenching from a temperature above the $\gamma^{\prime}$-solvus was necessary in order to dissolve the coarse $\gamma^{\prime}$, which had formed during slow cooling in the massive HIP plant. After this heat treatment, from each unHIPed and HIPed material, two specimens were machined. One specimen was tested at a very high
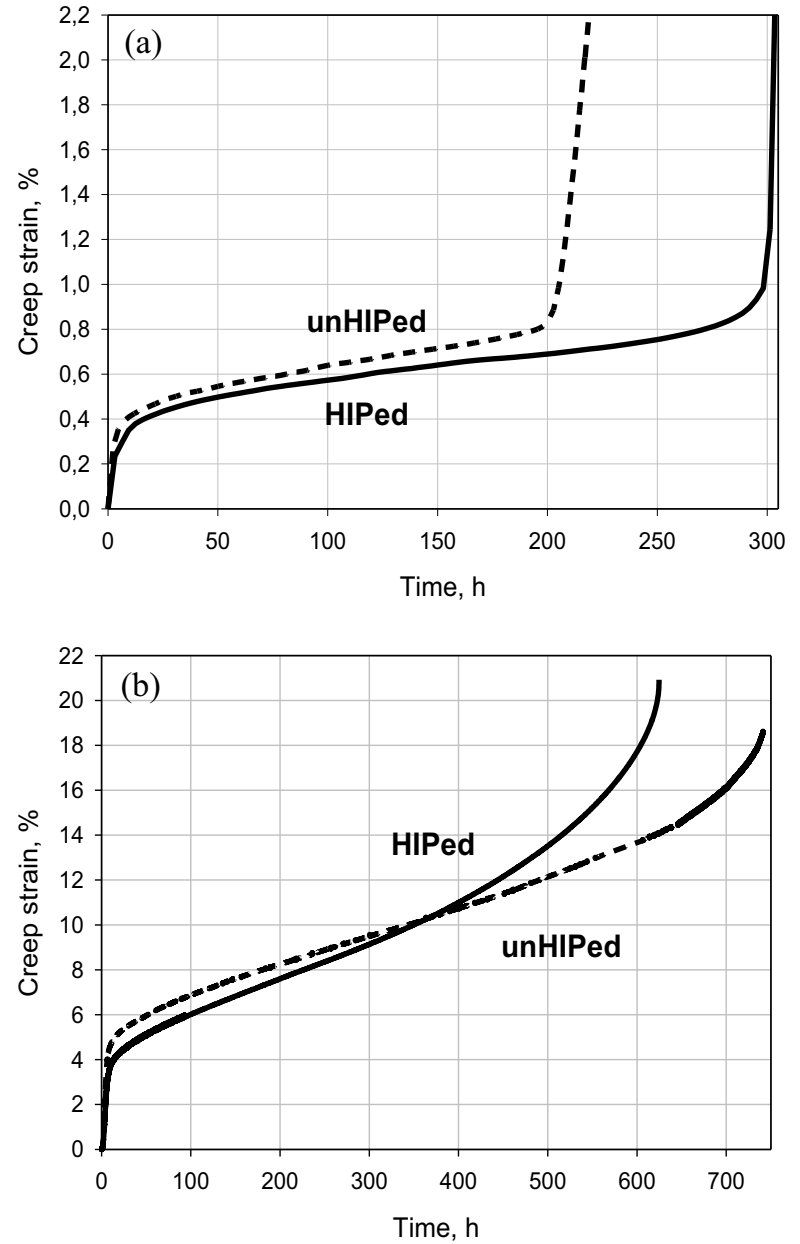

Figure 5. Creep curves of unHIPed and HIPed specimens of CMSX-4 at $1150{ }^{\circ} \mathrm{C} / 100 \mathrm{MPa}$ (a) and $750^{\circ} \mathrm{C} / 780 \mathrm{MPa}$ (b).

temperature $1150^{\circ} \mathrm{C}$ and $100 \mathrm{MPa}$ (like in $[7,8]$ ), the other one at a low temperature $750{ }^{\circ} \mathrm{C}$ and $780 \mathrm{MPa}$. The obtained creep curves are shown in Fig. 5. One can see that at both temperatures HIP has no effect on primary creep. The differences of the creep lifetimes of the unHIPed and HIPed specimens are within the usual scatter of such creep tests.

Similar high temperature creep tests, at $1150{ }^{\circ} \mathrm{C} /$ $100 \mathrm{MPa}$, were performed for the superalloy VGM4. Six specimens, three HIPed and three unHIPed ones, were tested under these testing conditions. The obtained mean values and standard errors for the HIPed and unHIPed specimens are respectively $163 \pm 25 \mathrm{~h}$ and $178 \pm 32 \mathrm{~h}$, so the found difference is within the statistical scatter. This investigation is described in detail in [9].

\section{Discussion}

The mechanism for pore closure in single-crystal superalloys is discussed in literature because this question is interesting under practical and academic aspect. For practice it is important to know how to remove porosity without material damage and with minimal processing costs. Under academic aspect it is interesting to know how the pores shrink in single-crystal material 
Table 1. Effect of HIP on mechanical properties of single-crystal nickel-base superalloys.

\begin{tabular}{|l|l|l|l|l|l|l|l|l|l|}
\hline \multicolumn{2}{|l|}{ Test } & Property & $20{ }^{\circ} \mathrm{C}$ & $550{ }^{\circ} \mathrm{C}$ & $700{ }^{\circ} \mathrm{C}$ & $750{ }^{\circ} \mathrm{C}$ & $850{ }^{\circ} \mathrm{C}$ & $950{ }^{\circ} \mathrm{C}$ & $1150{ }^{\circ} \mathrm{C}$ \\
\hline \multirow{2}{*}{ Fatigue } & HCF & Life & Y $[13]$ & Y $[12]$ & & $\mathrm{Y}[12]$ & $\mathrm{Y}[13]$ & & \\
\cline { 3 - 11 } & Life & & & $\mathrm{Y}[\mathrm{P}]$ & & $\mathrm{N}[\mathrm{P}]$ & $\mathrm{N}[14]$ & \\
\hline \multirow{2}{*}{ Creep } & Strain rate & & & & $\mathrm{N}[\mathrm{P}]$ & & & $\mathrm{Y}[7,8] ?, \mathrm{~N}[\mathrm{P}]$ \\
\cline { 2 - 10 } & Life & & & & $\mathrm{N}[\mathrm{P}]$ & & $\mathrm{Y}[14] ?$ & $\mathrm{~N}[7,8], \mathrm{N}[\mathrm{P}]$ \\
\hline \multicolumn{2}{|l|}{ Tension } & Strength & $\mathrm{Y}[15] ?$ & & & & & & \\
\hline
\end{tabular}

Y: clear HIP effect, N: no effect, ?: result doubtful, P: present work.

at a very high homologous temperature. The solidus temperature of CMSX-4 is about $1340{ }^{\circ} \mathrm{C}=1613 \mathrm{~K}$, so the HIP temperature $1288^{\circ} \mathrm{C}=1561 \mathrm{~K}$ corresponds to the homological temperature $T / T_{S}=1561 \mathrm{~K} / 1613 \mathrm{~K} \approx$ 0.97. Two main mechanisms for pore closure in singlecrystal superalloys are discussed: pore closure by plastic deformation, usually assumed for HIP, and pore closure by diffusional flow of vacancies emitted from the pore surface [10]. In our work the pore closure by dislocation slip was identified as the mechanism operating under the considered HIP conditions. Authors of the diffusion model give as reason for their approach the absence of recrystallization during HIPing, which they expect to occur in case of plastic pore closure. However it was shown in [11], that mainly the high dislocation density of cold pre-deformation is critical for recrystallization at high temperature, while hot pre-deformation is less dangerous, because in this case dislocations annihilate dynamically. Intensive dislocation annihilation during HIP is consistent with our TEM results of a shrinking pore in CMSX-4. The dislocation density around this pore was found to be much lower than it would be expected from the calculated plastic strains.

On base of the identification of octahedral dislocation slip as the HIP mechanism, a mathematical model for the kinetics of pore annihilation was developed. The performed modeling gave a shape of the pore annihilation curve $V_{p}=f(t)$ similar to the experimental one but the theoretical annihilation rate is higher. The discrepancy between modeling and experiment could be caused by the following reason. The tensor equations describing the viscous octahedral slip $\langle 011\rangle\{111\}$ consider creep anisotropy, but they were calibrated using just creep curves of [001] specimens. Consequently the effect of orientation on creep rate has to be thoroughly investigated and considered in the creep equations.

The effects of HIP (removal of pores) on the results of fatigue, creep and tension tests, reported in literature and obtained in the present work, are summarized in Table 1. A significant effect is marked with " $\mathrm{Y}$ " and " $\mathrm{N}$ " stands for no effect. "?" marks results under doubt and the reference "P" stands for present work.

For HCF of CMSX-4 a dramatic improvement was reported in [12]. For plain specimen rotating bend $\mathrm{HCF}$ testing at $550{ }^{\circ} \mathrm{C}$, the $10^{7}$ cycle strength is increased by $95 \%$; in notched $\left(\mathrm{K}_{\mathrm{T}}=2.2\right)$ axial $\mathrm{HCF}$ testing at $750{ }^{\circ} \mathrm{C}$ by $60 \%$. In [13] $\mathrm{HCF}$ results of PWA 1480 at room temperature and $843{ }^{\circ} \mathrm{C}$ are presented. At room temperature HIP increases the HCF life by several orders of magnitude, while at $843^{\circ} \mathrm{C}$ just by a factor between 2 and 12 , depending on the maximum stress $\sigma_{\max }$ in the cycle, see Fig. 6.

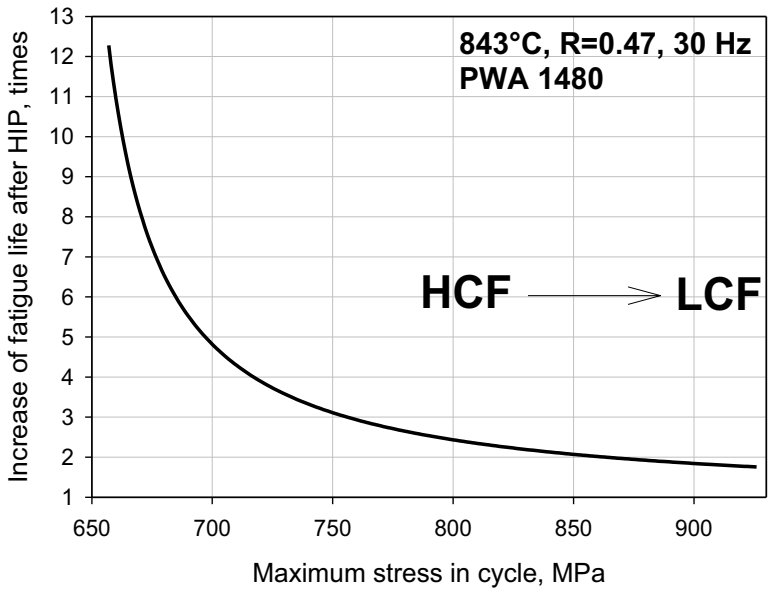

Figure 6. Factor for the increase of fatigue life of PWA 1480 at $843^{\circ} \mathrm{C}$ after HIP. Graphic calculated using data published in [13].

For LCF, according to our results, the life of CMSX-4 at $700{ }^{\circ} \mathrm{C}$ increases by about 12 times, however at $850{ }^{\circ} \mathrm{C}$ no effect of HIP on the LCF life of VGM was found. This is in agreement with the results for CMSX-4 at $950{ }^{\circ} \mathrm{C}$ reported in [14].

It follows from Fig. 6, that the effect of HIP on fatigue life is stronger for lower stress levels (HCF) than for high stress levels (LCF). This is not surprising: HIP should have a stronger effect at low stress levels when material elastically deforms. In this case specimens without pores can experience a large number of loading cycles without rupture, while in porous specimens stresses concentrate at pores, resulting in local plastic damage and, finally, cracks.

The effect of HIP on fatigue strength decreases with rising temperature for both, $\mathrm{HCF}$ and $\mathrm{LCF}$, and above $850^{\circ} \mathrm{C}$ it vanishes. This has following reasons. At higher temperatures the material plastically damaged at pores recovers by dislocation annihilation as well as the superalloy ductility significantly increases. At temperatures above $850{ }^{\circ} \mathrm{C}$ surface oxidation becomes critical for crack nucleation.

Concerning creep, there is no reason to expect an effect of HIP on primary and secondary creep because in this range the $\gamma / \gamma^{\prime}$-microstructure determines the creep rate. This was confirmed by our creep tests of CMSX-4 at $1150{ }^{\circ} \mathrm{C} / 100 \mathrm{MPa}$ and $750{ }^{\circ} \mathrm{C} / 780 \mathrm{MPa}$, where special care was taken to have the same orientation and $\gamma / \gamma^{\prime}$ microstructure for HIPed and unHIPed specimens. Thus "HIP effect on the creep kinetics" reported in $[7,8]$ probably results from different specimen orientation or $\gamma / \gamma^{\prime}$-microstructure. A significant HIP effect should be neither expected for the creep lifetime. Stresses at pores 
should relax by local creep without essential local damage, as long as the creep rate is not too fast. So, only in the final stage of tertiary creep cracking from pores occurs. This fits with our results obtained for VGM4 at $1150^{\circ} \mathrm{C} / 100 \mathrm{MPa}$ as well as with $[7,8]$ where very similar creep lifetimes were obtained for unHIPed and HIPed CMSX-4 specimens tested at $1150{ }^{\circ} \mathrm{C} / 100 \mathrm{MPa}$, namely about $246 \pm 57 \mathrm{~h}$ for unHIPed condition and $256 \pm 68 \mathrm{~h}$ for HIPed condition (data digitized from graphics in [7,8]). Contradictory to these results are those of [14], which were obtained by comparison of only two tests of CMSX-4 at $950^{\circ} \mathrm{C} / 355 \mathrm{MPa}$ and therefore marked by "?" So Table 1 shows, that in general there is no HIP effect on creep rate nor creep lifetime.

Finally, it was reported in [15] that HIP significantly increases the strength of the [111] loaded samples of a $2^{\text {nd }}$ generation superalloy at room temperature by increasing the strain hardening of specimens with such an orientation. This unexpected result obtained by comparison of only two tests obviously needs verification.

\section{Conclusions}

1. The pore shrinkage mechanism during commercial HIP of single-crystal nickel-base superalloys is plastic deformation on the octahedral slip system. With this mechanism, the kinetics of pore annihilation during HIP was modeled using crystal plasticity and large strain theory. The modeled annihilation curve $V_{p}=f(t)$ has a similar shape as the experimental one but the theoretical annihilation rate is higher. Thus a model refinement is required.

2. HIP dramatically increases the fatigue strength (HCF and LCF) at $20-750{ }^{\circ} \mathrm{C}$, typical for the colder parts of the turbine blades, e.g. the blade root. With increasing temperature, the effect of HIP on fatigue decreases. Above $850^{\circ} \mathrm{C}$ HIP has no significant effect on LCF life. HIP has a stronger effect for HCF than for LCF.

3. Creep tests of CMSX-4 and VGM4 showed, that HIP has no effect on the kinetics of creep nor on creep lifetime.
4. For comparative tests it is important, that unHIPed and HIPed specimens have the same orientation and $\gamma / \gamma^{\prime}$-microstructure. Otherwise the effect of orientation and microstructure can be stronger than that of pore annihilation.

\section{References}

[1] A. Epishin, T. Link, U. Brückner et al., Materials for Advanced Power Engineering, ed. by J. LecomteBeckers et al. (FZ Jülich 2002) 217

[2] K. Harris, G.L. Erickson, S.L. Sikkenga et al., Superalloys 92, ed. by S.D. Antolovich et al. (TMS 1992) 297

[3] N.V. Petrushin, I.L. Svetlov, A.I. Samoylov et al., Int. J. Mat. Res. 101 (2010) 594

[4] DFG report PO 405/7-1, RE 688/41-1 (TU BerlinBAM 2005)

[5] A. Epishin, T. Link, G. Nolze, B. Fedelich, Mater. Sci. Eng. (to be published)

[6] A. Epishin, B. Fedelich, T. Link et al., Mater. Sci. Eng., A 586 (2013) 342

[7] D.C. Cox, PhD dissertation, University of Cambridge (2000)

[8] R.C. Reed, D.C. Cox, C.M.F. Rae, Mater. Sci. Eng., A 448 (2007) 88

[9] I.L. Svetlov, I.V. Ishodjanova, A.G. Evgenov et al., Deformation and Rupture of Materials, 3 (2011) 28 (in Russian)

[10] B. Bokstein, A. Epishin, V. Esin et al., Defect and Diffusion Forum, 264 (2007) 79

[11] R. Bürgel, P.D. Portella, J. Preuhs, Superalloys 2000, ed. by T.M. Pollock et al. (TMS 2000) 229

[12] K.P.L. Fullagar, R.W. Broomfield, M. Hulands et al., Trans. of ASME, 118 (1996) 380

[13] L.G. Fritzemeier, Superalloys 1988, ed. by S. Reichman et al. (TMS 1988) 265

[14] J.-C. Chang, Y.-H. Yun, C. Choi, J.-C. Kim, JMEPEG, 12 (2003) 420

[15] F. Ebrahimi, E.F. Westbrooke, Acta Mater., 56 (2008) 4349 